\title{
Variability in the motion behaviour of intertidal gastropods: ecological and evolutionary perspectives-ERRATUM
}

C. CHAPPERON AND L. SEURONT

doi:10.1017/S002531541000007X, Published by Cambridge University Press, 20 April 2010

Equation 6 should appear as in the correct equation shown below. This typographical mistake did not affect the results reported in our article, and the values provided for the turning angle $\theta_{e}$ are correct.

$$
\theta=\arccos \left(\frac{\left(p_{1} p_{2}\right)^{2}+\left(p_{2} p_{3}\right)^{2}-\left(p_{1} p_{3}\right)^{2}}{2\left(p_{1} p_{2}\right)\left(p_{2} p_{3}\right)}\right)
$$

\section{REFERENCE}

Chapperon C. and Seuront L. (2011) Variability in the motion behaviour of intertidal gastropods: ecological and evolutionary perspectives. Journal of the Marine Biological Association of the United Kingdom 91, 237-244.

First published online 30 August 2011 